\title{
Persuasion as a Communication Tool ${ }^{1}$
}

\author{
Laura Gorham, Ricky Telg, and Tracy Irani²
}

\section{Introduction}

It can be argued that all types of communication involve some form of persuasion. Persuasion attempts to influence or convince others to take a specific action or to reach a certain conclusion about an issue. When we argue for our point of view, we are engaging in persuasion. When we present information as part of a claim or statement, we are being persuasive.

What is the difference between information and persuasion? Information can be neutral or biased, but it is generally intended to show evidence, facts and details about something. Persuasion uses information as part of an attempt to make claims or assertions designed to reinforce or change beliefs and behaviors. Think about a time when you wanted your parents to do something for you, such as buy you a special birthday gift, let you stay up late, or go out with your friends. Your attempts at persuasion probably focused on communicating specific reasons why your parents should take the action you wanted. Persuasion is a communication tool that can be adjusted to convince a single person, or to move an entire audience to a desired action. In this publication you will learn several techniques for persuasive communication.

\section{Strategies for Persuasive Communication}

Persuasive communication involves the use of strategies that are designed to create a convincing argument. These argument strategies include the following:

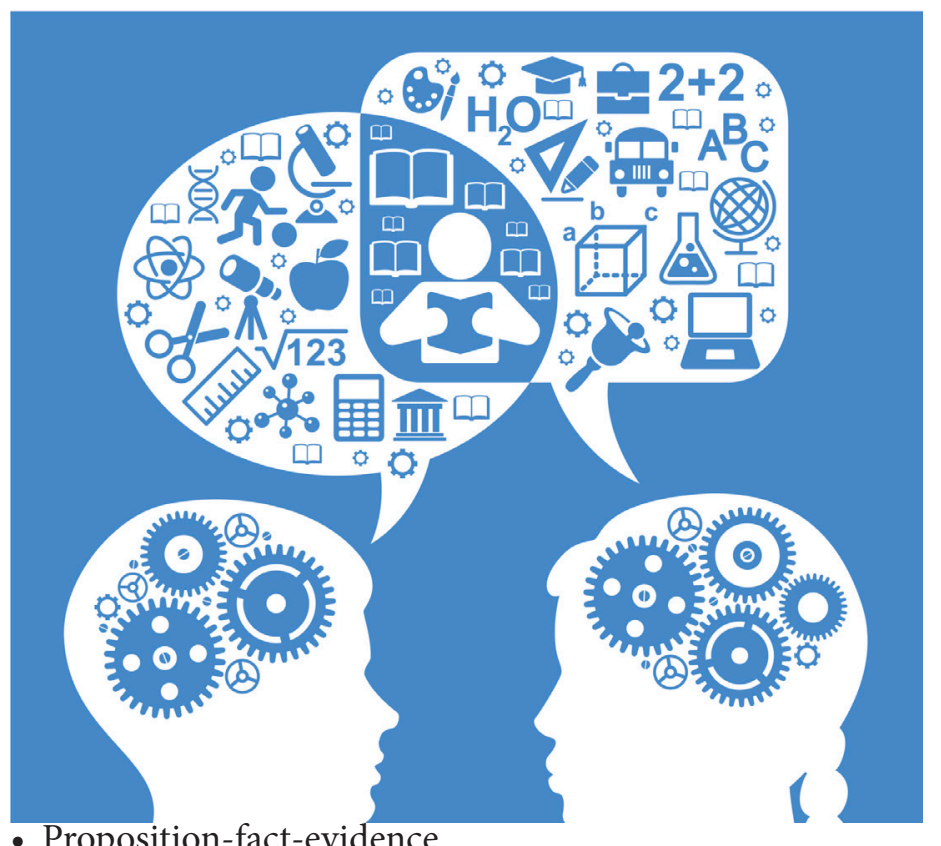

- Proposition-fact-evidence

- Common ground

- Logical reasoning (induction, deduction, comparison)

\section{Proposition-Fact-Evidence}

In this strategy, you begin with a basic proposition, then support that proposition with facts and forms of evidence. A proposition is a claim indicating your position on an issue. It can also be your proposed solution to a problem. Facts are statements of what is known to be true in a given situation; evidence includes any proof you have that helps you argue your main points. Evidence may include

1. This document is AEC481 (formerly WC144), one of a series of the Agricultural Education and Communication Department, UF/IFAS Extension. Original publication date July 2013. Visit the EDIS website at http://edis.ifas.ufl.edu.

2. Laura Gorham, graduate student; Ricky Telg, professor; and Tracy Irani, professor, Agricultural Education and Communication Department, UF/IFAS Extension, Gainesville, FL 32611. 
testimonials and statements that support your claim, cited documents, literature, or statistics.

\section{Common Ground}

Common ground refers to taking polarizing viewpoints and showing where they agree. The idea is to find enough areas of agreement to show that the two sides are more similar than different, and thus stimulate a compromise where a consensus can be reached. This strategy is particularly effective when there are two opposing sides to a controversial issue.

\section{Logical Reasoning}

Logical reasoning can be defined as a way of thinking. Logic is an important part of our thinking processes, although sometimes we let emotions influence our thinking. As part of a persuasive argument, the writer or speaker draws on logic and reasoning to support claims and refute or preempt objections. There are three types of logical reasoning:

- Induction

- Deduction

- Comparison

Induction involves moving from particular facts to general conclusions. Induction occurs when a person looks at a set of facts and makes an educated guess to explain them. Induction is used in science, where the inductive reasoning a scientist makes is called a hypothesis. For example, a plant scientist might investigate which variety of plant can best withstand drought-like conditions. Drawing on a large number of factors, such as the plant type, soil, and climate conditions, the scientist uses induction to make a hypothesis about which plant might work best.

Deduction is when the writer or speaker moves from the general to the particular. Deductive reasoning starts with a general principle, then applies the principle to a fact and finally draws a conclusion concerning the fact. The deduction process can be best illustrated with an often-used syllogism:

- All professional golfers are good athletes.

- Judy is a professional golfer.

- Therefore, Judy is a good athlete.

A syllogism is a logical argument with three propositions or claims: a major premise (All pro golfers are good athletes), a minor premise (Judy is a pro golfer) and a conclusion (Judy is a good athlete). The conclusion is a deduction made from the major and minor premises. A good deduction requires careful analysis of the premises upon which it is based. In the syllogism above, the conclusion is only true if being a good golfer automatically makes you a good athlete.

Comparison is a form of logical reasoning in which writers and speakers offer choices between or among alternatives based on a set of standards or criteria. To effectively use comparison, you must distinguish clear differences and similarities between the things you are comparing. As a persuasive technique, comparisons can be used when making a recommendation or proposing an action or solution to a problem. Advertisers and marketers tend to use comparison in order to persuade consumers to buy their product over someone else's. In Extension communication, it could be comparing two practices, such as using a rain barrel or tap water to irrigate plants.

Table 1.

\begin{tabular}{|l|l|}
\hline Rain barrel irrigation & $\begin{array}{l}\text { Tap water irrigation } \\
\text { Wo fee }\end{array}$ \\
$\begin{array}{l}\text { Wainwater fee } \\
\text { plants }\end{array}$ \\
$\begin{array}{l}\text { Reduced storm water runoff } \\
\text { Can be painted or } \\
\text { ornamented }\end{array}$ & $\begin{array}{l}\text { Tap water contains fluoride and } \\
\text { other inorganic compounds } \\
\text { No reduction of runoff }\end{array}$ \\
\hline
\end{tabular}

After making a head-to-head comparison such as the above, the writer or speaker ends with a call to action, which prompts consumers to conclude that, based on the comparison, they should purchase the advertiser's product.

\section{Summary}

Persuasion is such a common part of everyday communication that we're not always aware of it, but changing the opinions and behaviors of masses of people takes a much more concentrated effort. Backing up propositions with facts and evidence, finding common ground on divisive issues and using logical reasoning are three very effective techniques to not only inform your audience, but influence their thoughts and actions as well.

\section{References}

Telg, R.W. \& Irani, T.A. (2012). Agricultural communications in action: A hands-on approach. Delmar Cengage Learning: Clifton Park, NY. 